\title{
A New Approach to College English Teaching Based on Group Cooperation
}

\author{
Jie Zeng \\ School of Foreign Languages, Chengdu Normal University, Chengdu City, Sichuan Province, \\ 611130, China
}

Key words: group cooperation; College English; teaching reform

\begin{abstract}
Group cooperative learning can improve the overall level of the team through helping each other and jointly completing a task. It helps students to overcome the anxiety of language learning, form a sense of teamwork and feel the joy of learning English. Based on the author's learning and practical experience, this paper firstly analyzed the characteristics of the group cooperative learning model and then put forward the strategy of cooperative learning; finally, it pointed out the problems that should be paid attention to. The results of this study can not only provide students with the ability of cooperation and coordination, but also enable them to have a better English learning atmosphere to solve the problem together so that their English learning skills and levels can be fully improved.
\end{abstract}

\section{Introduction}

Group cooperative learning is a cooperative learning based on the interaction among students. Some domestic scholars define it as: group cooperative learning is a kind of aim with the purpose of promoting students to cooperate with each other and achieving common goals, which is based on the overall score of the group as the reward of the teaching strategy system. At present, the ultimate goal of English teaching is to improve students' comprehensive ability in using English. Group learning unites the team members to discuss the problem in English. This can not only provide students with the ability to cooperate and coordinate, but also allows them to have a better learning atmosphere to solve the common problems so that their English learning skills and levels can be fully improved.

\section{Characteristics of Group Cooperative Learning Model}

Interdependence. The team members in the cooperative learning group play different roles in order to achieve a common goal and the team leader can assign tasks to everyone. They are independent individuals, and are interdependent communities, who can not be separated. Finally, they worked together to achieve the same idea and their tacit understanding is very high, so this is their interdependence.

Democratic equality. Each student's English basis, personality, learning experience and methods are not the same. However, group cooperative learning will make no differences in the process of learning cooperation; there is no study of the high and low points in learning cooperation. In order to achieve the common goal, team members maximize their advantages and make full use of resources of each members to work in cooperation with a due division of labor. This model allows each team members to have a sense of democracy and equality and also their enthusiasm and interest in learning becoming more and more intense.

Mutual communication. As is known to all, the traditional education mode over the years has regarded the development and progress of students as knowledge; likewise, the learning process is equivalent to the process of mastering knowledge from the traditional perspective. However, cooperative learning has abandoned the traditional learning model; instead, it is a new 
learning mode full of dialogue and communication and team members communicate with each other. In the process of communication, thought has been spread and inspired, which is a process of learning to restore the nature of life. This is worthy to learn.

Extension. Group learning is not a step-by-step process that teacher guided. It has the participation and the interactive link. In addition to discussing topics related to learning tasks, each team member unconsciously has a lot of learning abilities in the process of cooperative learning, such as leadership, unity and cooperation ability, tolerance of others, appreciating the merits of others, etc. These extended features have improved the application abilities of college students.

Social adaptability. Compared with the traditional monologue learning, cooperative learning is closer to the real life. Students have to face competition, cooperation, listening ability, self expression and interpersonal interaction; at the same time, they should share the successes, failures, conflicts and contradictions with the team members, which are the necessary survival skills in real life. Therefore, the group cooperative learning is the practice of the students to adapt to the society, and it is very important to cultivate the students' psychological quality.

\section{Application Strategies for Group Cooperative Learning}

Comprehensive understanding of students with scientific and reasonable grouping to ensure the fairness of cooperative learning. In the early stage of teaching, teachers can understand students through English proficiency tests, questionnaires, interviews and classroom observations. The students are comprehensively divided into several groups in accordance with basic English, personality, hobbies, communicative competence, gender ratio and other factors. Group size is generally suitable for 4 to 6 students. When grouping, we should not only focus on the diversity of the group members, but also reflect the differences among the members of the group. Moreover, the level of each group should be close and should reflect the balance of the strength of each group so that to ensure the team learning is conducted in a competitive environment.

Determine the appropriate goals with refining the learning tasks to ensure the effectiveness of cooperative learning. Before the group cooperative learning, the teacher should guide the students to understand the target of language knowledge and language skills, and then the macro English learning tasks are divided into different sub tasks so that to guide students to make reasonable learning goals according to their own reality. Each group handles the task with the corresponding distribution. The task is completed independently by the members and discussed together with their own opinions, so that the final conclusion is formed after integration.

Take a variety of ways to reflect the main body and ensure the fun of cooperative learning. The main body of cooperative learning should be students. The teacher is only the distributor of the learning task, the monitor of the learning process and the evaluation of the learning outcomes. On the basis of group cooperation, teachers should carry out various teaching activities around the learning task, such as classroom discussions, experiential teaching, open debate, mock interviews, role play, etc. Thus, the students can maximize themselves to participate in the whole process of English learning. Group cooperative learning activities can be divided into three parts and there are 8 study groups in the class, which are divided into 3 "explain groups" and the "5 "explain groups" in the form of drawing. The "explain group" is responsible for explaining the language points and long sentences, and the "question group" is responsible for the designing the problem to the "explain group" and select the members of this group to answer the questions (each "question group" must presents at least 2 different questions). Whether it is the "explain group" and "question group" or not, it is necessary to carry out independent inquiry and cooperative learning; otherwise, it is difficult to complete the task of 
group learning. Students ask question and answer it in the process of a question and an answer so that the boring language knowledge becomes interesting.

Objectively evaluate on students and pay attention to the learning process to ensure the persistence of cooperative learning. The characteristic of group cooperative learning determines the diversification of its evaluation. In order to embody objectivity, evaluation should be carried out from three aspects: self evaluation, group evaluation and teacher evaluation. This not only concerns with the results of group cooperative learning, but also focuses on the process of cooperative learning. This process pays more attention to the students' emotional attitude, participation, will quality and the progress of English learning. Cooperative learning is carried out in college English teaching, and teachers mainly evaluate the performance of each group, so it is impossible to give consideration to every student. In order to test the effect of group members. We take the group as a unit to take dictation in English for the members of the group, answer content of the text questions and retell the dialogue and text and other activities. We can evaluate the performance of group members in the process of cooperative learning in groups so that students in a timely manner to reflect and make multi comparison, which will find their own shortcomings and adjust learning strategies for greater progress.

\section{The Problems That Cooperative Learning Should Pay Attention to}

Grasp the role of teachers to play a leading role in group cooperative learning. When students encounter difficulties, teachers should give advice for them; when the ice or debate phenomenon appear in the discussion, teachers should take measures to intervene. Teachers should always grasp the rhythm of group cooperative learning and control the burst phenomenon in the process of cooperative learning, which will lead the team to learn in an orderly manner and ultimately complete the task of learning English and improve the efficiency of classroom teaching.

Choose a good way to avoid cooperative learning into a mere formality. According to the specific content of the teaching and the actual situation of the students, the teacher should rationally choose the way of learning activities to provide students with the necessary English learning materials, learning resources and independent thinking time so that to enable students to complete the learning task through independent inquiry and group cooperation. Teachers should also play the leading role of excellent students and encourage students with poor English foundation to overcome inferiority complex, the afraid of making mistakes so that to speake English loudly, which can make progress in English listening, speaking, reading, writing, translation and other aspects for different levels of students.

Make good use of evaluation on combination of quantitative evaluation and qualitative evaluation. There are two kinds of evaluation methods: quantitative evaluation and qualitative evaluation. Quantitative evaluation can be applied in the whole process of group cooperative learning; the quantitative evaluation can be carried out from the group's pre-class preparation, classroom performance, unit knowledge points detection and extracurricular self-study and other aspects. Content that cannot be quantified including the emotional attitude, participation, will quality and English progress in the process of group cooperative learning, and it is supplemented by qualitative evaluation for the students. For students' individual or team performance, teachers should use motivational language. As for the universal or serious problems in students' learning, teachers should put forward some pertinent and constructive suggestions to students and promote them to cooperate actively and effectively.

\section{Summary}

Although many people have differences in understanding and expressing cooperative 
learning, they share the connotation of cooperative learning and positive energy. Under the premise of ignoring the traditional mode, teachers pay more attention to the interaction and participation of the students and incorporate the group cooperation into college English classroom teaching. Thus, a classroom teaching mode characterized by the interaction among students and was came into being. In order to promote students' individual performance and group collaborative development, cooperative learning has become the main goal of college English teaching. The application of group cooperative learning mode in college English teaching is not only the need of curriculum, but also the ability of cooperation, which meet the needs of today's society for applied talent and is worthy to carry out an in-depth implementation. When using this idea, teachers should constantly change their teaching methods, renew their views and understand the connotation so that the group collaborative learning can promoting college English teaching in a true sense. From the teaching strategy, the main body of cooperative learning is teacher. Therefore, in the process of cooperative learning in college English teaching, teachers should have a goal and teach class step by step. But in practical terms, the application process is complex and difficult. This requires teachers to work hard, make in-depth study and cooperative learning so as to promote the optimization of college English teaching.

\section{References}

[1] Zheng Suhua. The Application of Cooperative Learning Strategy in College English Teaching[J]. Journal of Shanxi Normal University(Social Science Edition), 2006, S1: 159-161. [2] Cao Yeqiu. The Application of Cooperative Learning Strategy in College English Teaching[J]. Education exploration, 2013, 12: 36-37.

[3] Qi Cong, Yu Chao. The Application of Group Discussion in College Oral English Teaching[J]. Heilongjiang Education(Heilongjiang Education), 2011, 03: 89-90.

[4] Yu Lan. The Nature of Cooperative Teaching and the Professional Development of College English Teachers[J]. Journal of Shenyang Normal University(Social Science Edition), 2012, 05: 126-128.

[5] Zhang Xiaoqin. A study on small and medium composition learning in Distance Education English teaching[J]. Contemporary Educational Science, 2012, 18: 58-59.

[6] Wang Hua. The Application of “Group Cooperative Learning” in English Teaching[J]. Journal of Guizhou Institute for Nationalities(Philosophy and Social Sciences Edition), 2007, 04: 138-140.

[7] Huang Jianguo, Xia Qin. The application of group cooperative learning in English teaching[J]. Chinese National Education, 2014, 10: 50-51. 